\title{
Del ateísmo postcristiano a la indiferencia postmoderna. Génesis de una situación cultural
}

\author{
José Ignacio González Faus, \\ Facultad de Teología de Cataluña, \\ Centro de Reflexión Teológica, San Salvador.
}

N.B. El artículo que sigue ha nacido en un contexto europeo (cs muy posible que el problema latinoamericano no esté tanto en cl atcísmo cuanto en las sectas). De todos modos, y dada la influencia y la colonización cultural y tcológica europea. este artículo puede ser útil pard comprender una mentalidad que nos llega de mil maneras y también un peligro que acabará amenazárıdonos. conforme avance la secularización de la sociedad. La lesis del artículo es que el ateísmo occidental no es un problema de no creencia en la idea de Dios o de no llegada hasta Dios, sino de pérdida de confianza. y por ello de fe. en el Dios crisiano. No es pues un ateísmo precristiano, sino posicristiano. Y. probablemenle, liene mucho que ver con una pérdida de credibilidad de la Iglesia. Esa pérdida de re-confianza es un acontecimiento Iraumático y desala un proceso cultural que el artículo intenta poner de relieve mediante una serie de textos cronológicaments encadenados. El trauma acaba resolviéndose en la indiferencia postmodema. Queda la pregunta de si, para América Latina, es inevitable y necesario incorporar esa insensibilidad, junto con la oportuna importación de una tecnología occidental (de ahí el rápi. do texto de Mario Benedetti con que Tinaliza el artículo).

"No es el modo como una persona habla de Dios lo que me permise saber si ha morado en el fuego del amor divino, sino el modo cono habla de las cosas terrenas" (Simone Weil).

Estas lineas pretenden encontrar la unidad de un proceso, en una determinada situación cultural de falta de fe. No tratan del ateísmo que sólo estudia a Dios 
por razones de coherencia lógica o racional, y que es muy anterior al cristianismo, y detectable ya en Demócrito o Lucrecio. No tratan de aquel Dios del que Zubiri se preguntaba cómo iba el hombre a rezar causa causarum miserere mei, sino del Dios a quien el hombre puede invocar como salvador. Por eso hablo de un ateísmo postcristiano.

A la vez, las líneas que siguen quisieran poner de relieve una concatenación de las ideas. No se discuten otros factores como pueden ser los condicionamientos sociales. (Por ejemplo, quien así lo quiera, tendrá derecho a argumentar que en un mundo en el que se está poniendo de moda la palabra "basura" contratos basura, telebasura etc.- es coherente que no haya demasiado sitio para Dios. O también tendrá derecho a argumentar que, en un mundo que ha erigido en Dios al dinero, no puede haber sitio para aquel Dios de quien Jesús decía: "no se puede servir a Dios y al dinero". Pero nosotros no vamos a tratar de eso.) Buscamos simplemente la coherencia lógica del proceso que lleva a nuestra actual situación histórica. Para ello nos limitaremos a yuxlaponer cronológicanıente unos textos claves, mostrando la dinámica que va llevando de un paso al otro.

Entre gentes de Iglesia es frecuente oír decir que la muerte de Dios supone la muerte del hombre. Teológicamente hablando es probable que las cosas sean mucho más complejas. Pero al menos sí cabe esperar, a nivel sociológico, que la muerte de una determinada idea de Dios implique un cambio en la imagen ideal del hombre. Veamos qué dan de sí los textos, antes de hablar de ellos.

\section{Jean Paul: No ha:" Dios ni més allá salvador}

Texto

Una tarde de verano me tumbé en un monte cara al sol, hasta que me fue venciendo el sueño. Soñé que me despertaba en un cementerio. Las ruedas del reloj de la torre, que daba las once, me habían despertado. Pensé que un eclipse habría cubierto el sol con la luna, y lo busque en el cielo nocturno. Todos los sepulcros estaban destapados, y las puertas de las tumbas se abrían y cerraban empujadas por manos invisibles. Sobre las paredes volaban unas sombras que nadie proyectaba, y otras sombras caminaban erguidas en el aire enrarecido. En las abiertas tumbas sólo dormían los niños. Colgaba del cielo una masa de nubes arrugada, pesada y gris, atraída por una sombra gigantesca, como por una red que las enlazaba cada vez más estrechamente y con más vehemencia.

A lo lejos of sobre mi cabeza una avalancha que cala, y bajo mis pies sentf las primeras sacudidas de un terremoto. La iglesia vacilaba en la base y en la cumbre, sacudida por un doble estertor inaudito que intentaba inútilmente convertirse en consonancia armónica. De cuando en cuando bullla de

Digitalizado por Biblioteca "P. Florentino Idoate, S.J."

Universidad Centroamericana José Simeón Cañas 
sus ventanas un resplandor lívido en el que chorreaban hierto y plomo derretidos. La red de las sombras y el ondear de la tierra me empujaron dentro del templo, en cuyas puertas dos basiliscos relampagueantes incubaban nidos venenosos. Fui moviéndome a través de sombras desconocidas sobre las cuales aparecía como estampada una antigüedad de siglos. Todas las sombras estaban dispuestas en torno al altar y a todas les temblaba y les batía el pecho en lugar del corazón. Sólo un difunto que había sido sepultado en la iglesia hacía poco, yacía lodavía sobre sus cojines sin que le temblase el pecho, $y$ en su rostro sonriente aleteaba un sueño feliz.

Al entrar allí un vivo, se despertó el difunto, dejó de sonreir, y levantó sus párpados con una contracción cansada: alli dentro no había ojos, y en su pecho latiente se abría una herida en el lugar del corazón. Levantó sus manos para juntarlas en oración, pero los brazos se alejaron y sc dispersaron, y las manos cayeron unidas. Arriba, en la boveda del templo, estaba el cuadrante de la eternidad sobre el cual no aparecía ninguna cifra ni saela; sólo un dedo negro hacía de indicador, y los muertos se esforzaban por adivinar en él al tiemipo.

De pronto cay6 sobre el altar otra figura noble con rostro de un inmenso dolor. Y todos le gritaron: " $\mathrm{C}$ Cristo! ¿existe un Dios?

- No existe", fue la repuesta.

La sombra de todos los difuntos fue sacudida por un sobresalto, y de resultas de aquel temblor cada uno se encontró separado de los demás.

Cristo prosiguio:

- "Anduve por los mundos, entré en los soles y recorri, volando con la vía láclea, todos los desiertos del cielo; pero no hay ningún Dios. Bajé hasta el abismo desde donde el ser lanza sus sombras, escruté en la vorágine y grité: 'Padre ¿dónde estás?'. Pero sólo of la eterna marejada a la que nadie gobierna, y allí -goteando sobre el abismo- estaba al centelleante arcoiris de los entes, sin ningún sol que lo hubiera producido. Y cuando levanté mi mirada sobre el mundo anonadado hacia el ojo divino, éste me miraba con una órbita vacía, sin fondo; y la eternidad se abatía sobre el caos tratando de triturarlo y rumiarlo. ¡Bramad todavla terremolos, gritad hasta que se deshagan las sombras, puesto que El no existe!".

Las pálidas sombras se extingufan en un vuelo voluble, igual que del hielo se difunde un vapor blanco, como un aliento cálido; y todo quedó hecho un vacío inmenso. Entonces se juntaron en el templo todos los niños difuntos, que se habían despertado en el cementerio, y se lanzaron hacia la alta figura que estaba junto al altar gritando: "Jesús ino tenemos nosotros un Padre?". Y El, estallando en lágrimas dijo: "Somos lodos huérfanos, voso- 
tros y yo; no tenemos padre alguno".

La intensidad de las sacudidas aumentó, los muros temblorosos del templo cayeron uno sobre otro, el templo y los niños se hundieron en el abismo $y$, con ellos, el sol y la tierra. Y todo el edificio cósmico, en toda su inmensidad fue diluyéndose en las profundidades, mientras arriba, en la cima de la naturaleza ilimitada, quedaba en pie Cristo, mirando fijamente hacia abajo, hacia el universo barrenado por mil soles, como si fuera una mina excavada en la noche eterna, por la que discurrían los soles como linternas subterráneas y las vías lácteas como venas de plata.

Y cuando Cristo recorrió con su mirada la desaparición tumultuosa de los mundos, la llamarada danzarina de los fuegos fatuos celestiales y los blancos corales de corazones latientes; cuando vio cómo todas las esferas iban lanzando una tras otra sobre el mar de los muertos las almas corroídas por una Ilama íntima, igual que un globo de agua esparce luces que parecen nadar sobre las olas, Cristo levantó los ojos hacia arriba hacia la nada y la inmensidad vacía, y dijo:

- " $¡$ Torpe nada muda, eterna necesidad fría caos loco! ¿Quién de entre vosotros puede saberlo? ¿Cuándo nos aniquilaréis al universo y a mi? ¿Lo sabes tú, azar? ¿tú que recorres el vértice de las nieves y de las estrellas con tus huracanes, y empujas con tu soplo un sol tras el otro, y haces callar a tu paso la rugiente luminosidad de las constelaciones? Oh Padre, Padre, ¿donde está tu pecho infinito para que repose sobre él? ¡Ah! Si cada yo es el padre y creador de sí mismo ipor qué no puede ser también su propio ángel exterminador?... Y éste que está aqur junto a ml, ¿es lodavfa un hombre? Ah desventurado: vuestra exigua vida es sólo un suspiro de la naturaleza, o mejor un eco. Un espejo cóncavo lanza sus reflejos sobre vuestra tierra, en esas nubes de polvo que nacen de las cenizas de los muertos, y así germináis vosotros, imágenes de sombras vacilantes. Mirad allá al fondo, hacia el abismo sobre el que navegan nubes de ceniza. Nieblas llenas de mundos se levantan del mar de los muertos, el futuro es una niebla ascendente, y el presente una niebla que se desvanece. ¿Reconoces tú tu tierra?".

En este momento Cristo miro hacia abajo; sus ojos estaban llenos de lágrimas. Y dijo: "En vano estuve sobre ella: en aquel tiempo era todav́a reliz, lodavía tenía a mi Padre infinito y todavla levantaba alegre la mirada sobre los montes, hacia el cielo ilimitado, aprelando mi pecho traspasado contra su imagen apaciguante; incluso en la amarga muerte podía yo decir: ¡Padre, saca a tu hijo de sus despojos cruentos y levántalo hasta tu corazón!... Oh vosotros, moradores dichosos de esta lierra: vosotros todavía creéis en El. Quizá vuestro sol está a punto de ponerse, y en medio de vuestras flores y vuestras lágrimas os ponéis de rodillas y levantáis las ma- 
nos felices y llorando de alegría, y mirando al cielo que se os abre grilais: 'Tú sí que me conoces, Infinito, y todas mis heridas las sanarás Tú tras la muerte'... ¡Ay desdichados! Luego de la muerte no quedarán sanadas vuestras heridas. Cuando el hombre se extiende sobre el suelo con su espalda cargada de tribulaciones, para que ese sopor le lleve a un mañana más bello. lleno de verdad, de virtud y de alegría, he aquí que se despierta en el caos proceloso, en la eterna medianoche. $Y$ no llega ningún mañana y ninguna mano sanadora y ningún padre infinito. Oh tú mortal que estás aquí junto a mí: adóralo si todavía vives, pues si no, ya lo has perdido para siempre".

Entonces miré hacia la tierra y puse mi mirada en el edificio radiante del mundo, y vi que se levantaban los anillos de la enorme serpiente de la eternidad, que estaba apretando el universo de los mundos, mientras sus espirales abrazaban el universo o hasta que se enroscó varias veces en torno a la naturaleza y aplastó los mundos unos contra los otros, y redujo a polvo el templo infinito hasta convertirlo en una iglesia de cementerio. Y todo fue haciéndose estrecho, térrico, angustioso. $Y$ un inmenso badajo iba ya a dar la última hora y a triturar el universo..., cuando me desperté.

Mi alma lloraba de gozo por poder adorar a Dios todavía. Y mi plegaria eran la alegría, las lágrimas y la fe en El. Cuando me levanté, el sol desaparecía denso tras las repletas espigas doradas, y arrojaba el reflejo pálido de su ocaso sobre una luna pequeña que subía por un mañana sin aurora. $\mathbf{Y}$ entre cielo y tierra desplegaba sus pequeñas alas un alegre mundo eff́mero, que vivía a mi lado cara al Padre infinito. $Y$ unos armónicos de paz se difundían en torno a mí desde toda la naturaleza, como de lejanas campanas vespertinas. (Jean Paul, Rede des toten Christus, vom Weltgebaüde herab, dass kein Gott sei, en Siebenkăs, Werke (Munich 1959, II) 266-271.)

\section{Comentario}

No parece que este texto tuviera, en su momento, gran resonancia o influjo. No es fácil encontrarlo en las historias de la filosofla. Quizá porque su estilo es más bien literario, romántico. Narra una sensación en lugar de conceptualizarla. Y se trata de una sensación de sinsentido, de ausencia de salvación. Ello confirma que nos enfrentamos con un ateísmo referido al Dios cristiano, y no a una noción "general" de Dios como explicación o "causa primera". Es bien significativo que el discurso esté en labios de Cristo.

Un análisis riguroso exige distanciarse de su romanticismo para no quedar prendidos en él, ni despreciar por él lo que se nos dice. Notemos:

a) En primer lugar la frase en cursiva del segundo párafo: "un estertor inaudito que intentaba inútilmente convertirse en consonancia armonica". Algo de eso es lo que intentará de hecho la postura número 2. Pero Jean Paul lo 
considera, ya de antemano, un empeño inútil.

b) El punto clave del texto es el desengaño de Cristo que se expresa sobre todo en el segundo párrato de su discurso ("anduve por los mundos, entré en los soles", etc.). Es Cristo el que ha fallado, el que nos ha engañado (y se ha engañado) con su promesa divina. El problema no es de solidez de una argumentación intelectual, sino de fiabilidad de una Promesa: " $i$ no hay buena noticia!". Y esto es bastante característico del ateísmo "postcristiano".

c) Luego de esto, el autor reconoce que la ausencia de Dios implica un caos: el primer párrafo del discurso de Cristo parece describir aquella "nada informe" ( se cernía sobre el caos" ( $c f r$. Gen I, 2).

d) Pero hay algo más: además de sinsentido, orfandad. Cristo rompe a llorar y exclama "todos somos huérfanos". No cabe pues una "instalación perfecla" (como dirá la postura 4) en ese caos y orlandad que es la finitud sin Dios.

e) La sensación de desesperación es tal que el mismo Cristo pregunta: si sólo el hombre es creador de sí mismo, si no hay ninguna razón amorosa para su existencia ¿por qué no puede ser también su propio exterminador?: el "ángel" exterminador no sería ahora instrumento de venganza, sino de liberación. Resuenan aquí anticipadamente (y se entienden mejor) las palabras con que, ya en el siglo XX, comienza El mito de Sísifo de A. Camus: "el único problema filosófico importante es el suicidio".

f) Y también resuena el final del mismo libro ("la única salida del hombre es imaginarse a Sísifo dichoso"), en el último párrafo del discurso de Cristo ("sobre la tierra .... todavía feliz"): mejor se está en la tierra con la mentira ilusionada de Dios, que fuera de ella en la verdad de la nada. Y ello pese a que en la tierra estamos "con nuestra espalda cargada de tribulaciones". A pesar de eso -concluye el cronista- este "alegre mundo efímero" es habitable porque crec existir "cara al Padre Infinito". Todo habfa sido sólo una pesadilla.

En conclusión: la buena noticia era falsa.

2. No existe Dios pero la humanidad es divina. O: no hay más allá, pero hay más acá (aunque sólo mañana).

A la situación antes descrita le sigue una doble reacción posible, según se mantenga o no la existencia de alguna "buena noticia".

\subsection{Primer texto}

La critica de la religión desemboca en la doctrina de que el hombre es el ser supremo para el hombre y, por consiguiente en el imperativo categbrico 
de echar por tierra todas las relaciones en que el hombre sea un ser humillado, esclavizado, abandonado y despreciable. (K. Marx, Contribución a la crítica de la filosofia del derecho de Hegel, Mew I, 385.)

\section{Comentario}

La buena noticia es otra: el futuro, y el "imperativo categórico" que se deriva de la nturaleza del hombre como "ser supremo".

Digamos como aclaración previa que este texto no parece tener cabida en nuestro recorrido, puesto que proviene de otra tradición: la que ve en la negación de Dios no sinsentido y orfandad para el hombre, sino liberación de unas cadenas metafísicas que le impedirf́an ser lo que el hombre es: divino'. Es conocida la frase de Marx ya en su tesis doctoral: "la filosofía no hace ningún secreto de esto. La afirmación de Prometeo 'sencillamente, odio a todos los dioses' es su propia afirmación, su lema contra todos los dioses, celestiales y terrenales, que no reconocen la conciencia que tiene el hombre de ser la divinidad suprema". A pesar de esto, el texto de Marx merecía ser citado por la polémica a que da lugar, y que está ejemplificada en los ataques de Marx a Stimer, que serán el objeto de nuestro comentario.

a) Cuando Marx escribe que "el hombre es el ser supremo para cl hombre", ¿quién es el sujeto de esla frase?, ¿el género humano?, ¿los demás? Entonces escribe Max Stirner (atacando sobre todo a Feuerbach)—, se trata de un ateísmo "beato", que me obliga a seguir doblando las rodillas ante un dios al que simplemente le han cambiado el nombre y le llaman "hombre ser supremo" en vez de "santísima trinidad". Según Stirner, si no hay Dios "no hay ninguna razón para que el hombre sea respetado" y, por tanto, la conclusión de la ausencia de Dios es que el hombre (es decir yo) soy el ser supremo para mí. "Dichosos los egolstas porque poseerán la tierra", concluye Stirner.

b) Esta argumentación deja muy incómodo a Marx: tanto que, en buena parte, responde insultando: si nosotros somos "beatos" Stimer es un "santo" (san Max, o san Sancho Panza, le llama porque, como aquél, piensa "con entrambas posaderas"). Decir como Stirner que "el hombre ha sido respetado siempre sólo por razón de un Ser Superior" es la fe que traslada montañas, porque fundamenta el respeto al hombre en un fantasma. Si ponemos otra vez las montañas en su sitio -continúa Marx-, lo que habria que decir es que "se ha honrado a un Ser Supremo, y se han reconocido fantasmas sólo por razón de los privilegiados, que se protegían y se privilegiaban de esta manera"2.

c) A pesar de esa respuesta, - y quizás porque él mismo no estaba satisfecho con ella- Marx abandonará en adelante ese lenguaje de "imperativo" y de "ser supremo": no existe ningún imperativo moral que obligue al amor contra el egoismo. Tanto el egoísmo como el espiritu de sacrificio son formas de 
autoafurmación, diversas según las circunstancias. La oposición entre egofsmo y amor "tiene un origen material, con lo que desaparece por sí misma", en cuanto se cambien las circunstancias materiales ${ }^{3}$.

d) Nótese finalmente cómo, en estas palabras, Marx profesa la misma "armonía preestablecida" que su gran enemigo Adam Smith. Este afirmaba que buscando sólo el interés personal, ya se consigue el social: la farnosa "mano invisible" se encarga de ello. Marx cree que buscado sólo el interés colectivo ya se realiza el personal. Ambos creen en los reyes magos: sólo que ahora no se llaman meichor, gaspar y balthasar, sino progreso, civilización y modernidad...4.

Y para que este optimismo ingenuo no desvirtúe la postura que estamos exponiendo, será bueno completarla con otro texto que va en la misma dirección, pero resulta históricamente más lúcido. Un personaje de Dosloyevski viene a decir que, ya que no hay Dios, no nos queda mós remedio que amamos mucho: no porque seamos divinamente amables, sino porque no tenemos otra cosa.

\subsection{Segundo texto}

... Admilamos que no creía mucho en Dios pero, a pesar de todo, no podía menos de sentir añoranza por su idea. No podía menos de imaginarme a veces de qué modo vivirfa el hombre sin Dios, y la posibilidad de que esto sucediera en algún tiempo... No tengo la menor duda de que esto sucederá...

Yo me imagino, querido amigo, que la lucha ya se terminó. Después de las maldiciones, el alboroto, los silbidos y tanto barro vertido, renació la calma y los hombres quedaron solos, tal como deseaban. Abandonaron la antigua idea sublime y se alejó el manantial de fuerza que les alimentaba, como se aleja el majestuoso sol en el cuadro cie Claude Lorrain.

Pero esto era ya como el último día de la humanidad. Los hombres comprendieron de pronto que se habían quedado completamente solos, y sintieron de golpe una gran orfandad. Querido muchacho, nunca pude imaginarme que los hombres fuesen irgratos y estuviesen embrutecidos.

Al quedar huérfanos, lo primero que harían los hombres es abrazarse estrechamente unos a otros. Se cogerían de las manos comprendiendo que, en adelante, ellos mismos eran todo cuanto les quedaba. Desaparecería la gran idea de la inmortalidad, y habría que sustituirla por otra; y todo el gran excedente del antiguo amor a Aquel que es la Inmortalidad, se encaminaría a la naturaleza. al mundo, al hombre y a cada brizna de hierba. Amarían la tierra y la vida apasionadamente, como se puede amar cuando se sabe que las existencias son efímeras y las vidas limitadas. Empezarian a observar y descubrirían en la naturaleza fenómenos y misterios que antes no sospechaban, pues la mirarían con ojos nuevos, con la mirada del amante a su mada.

Digitalizado por Biblioteca "P. Florentino Idoate, S.J."

Universidad Centroamericana José Simeón Cañas 
Al despertarse, tendrfan prisa por besarse y amar, puesto que los dlas son cortos, y eso es lo único que les queda y lo único que podrán poseer. Trabajarían uno para el otro, y cada uno daría al otro lo que le sobrase y serfa feliz. con ello. Los niños sentirían que todos son sus padres y madres.

"Admitamos que mañana sea el úllimo d́a - pensaría cada uno mirando al sol poniente. Da igual, yo moriré, pero quedan los demás y después de ellos sus hijos". Y csta idea de permanencia y de mutuo amor sustituiría a la de un encuentro en el más allá. ¡Cuánta prisa se darían en amar, para apagar la tristeza de sus corazones! Serfan orgullosos y audaces para si mismos. pero cada uno temblaría por la vida y la felicidad de los demás. Serian cariñosos y no sentirían vergüenza -como sucede ahora- de acariciarse como los niños. Al encontrarse se mirarían con ojos profundos y comprensivos, y en esas miradas habrfa amor y tristeza.

b

Amigo mio - se interrumpió de pronto con una sonrisa - todo esto es una fantasía, quizás incluso la más inverosímil. Pero yo me la imaginaba con gran frecuencia porque en loda mi vida no pude vivir sin esto y sin pensar en ello... Pero lo notable es que siempre terminaba mi cuadro con una visión, como la de Heine en "Cristo en el mar Báltico". No podía prescindir de él, no podía menos de imaginármelo allí, entre los hombres que se habían quedado huérfanos. Venía a ellos, les tendía las manos y decía: "¿Cómo pudisteis olvidarlo?". (F. Dostoievsky, El adolescente, parte 3", cap. 7.)

\section{Comentario}

a) Este texto tiene cierto carácter profético ("no tengo la menor duda de que esto sucederá"), al igual que el siguiente de Nietzsche. Pero empalma también con la sensación de soledad y orfandad expuestas por Jean Paul. Le une a él cierta lógica "práxica", diferente de esa "Iógica" reactiva que caracterizaba al texto de Marx. El amor al hombre ya no brota de ningún imperativo élico ni de circunstancias materiales ideales, sino de nuestra misma angustia, ino tenemos otra cosa! Se trata de un razonamiento más existencial que lógico, que retomará también Simone de Beauvoir, contradiciendo al razonar lógico-formal de Iván Karamazov ("si Dios no existe, lodo está permitido"). Simone arguye que, precisamente porque Dios no existe, no está todo permitido.

b) A la vez, el autor (y detrás de él Dostoyevski) califica toda esta hipótesis como "inverosímil". La llamada al amor era bonita, pero no gratuita. y el amor sólo llena cuando es gratuito. Era una llamada convulsiva y para salir de la tristeza. Por eso es inverosímil que semejante hipotesis pueda salvar al hombre.

Con elio se pone de relieve que este apartado tenía cierto carácter de paréntesis, o de primera reacción frente al desconcierto. Y se nos abren las puertas a las verdaderas consecuencias del texto de Jean Paul, que vendrán expuestas en el apartado siguiente.

Digitalizado por Biblioteca "P. Florentino Idoate, S.J."

Universidad Centroamericana José Simeón Cañas 


\section{F. Nietzsche: Ni hay Dios ni la humanidad es divina. Sólo queda "crear" el superhombre}

\subsection{Texto}

No oisteis hablar de aquel loco que en pleno dla corra por la plaza pública con una linterna encendida, gritando sin cesar: ¡Busco a Dios, busco a Dios! Como estaban presentes muchos que no creían en Dios, sus gritos provocaron a risa. ¿Se te ha extraviado? -decla uno. ¿Se ha perdido como un niño? - preguntaba otro. ¿Se ha escondido? ¿Tiene miedo de nosotros? ¿Se ha embarcado? ¿Ha emigrado? Y a estas preguntas acompañaban risas en el coro. El loco se encaró con ellos, y clavándoles la mirada, exclamo:

“¿Dónde está Dios? Os lo voy a decir. Le hemos matado, vosotros y yo, todos nosutros somos sus asesinos. Pero ¿cómo hemos podido hacerlo? ¿Cómo pudimos vaciar el mar? ¿Quién nos dio la esponja para borrar el horizonte? ¿Qué hemos hecho después de desprender a la tierra de la cadena de su sol? ¿Dónde la conducen ahora sus movimientos? ¿A donde la llevan los nuestros? ¿Es que caemos sin cesar? ¿Vamos hacia adelante, hacia atrás, hacia algún lado, erramos en todas direcciones? ¿Hay lodavía un arriba y un abajo? ¿Flotamos en una nada infinita? ¿Nos persigue el vacío con su aliento? ¿No sentimos frío? ¿No veis de continuo acercarse la noche, cada vez más cerrada? ¿Necesitamos encender las linternas antes del mediodía? ¿No oís el rumor de los sepultureros que entierran a Dios? ¿No percibimos aún nada de la descomposición divina?... Los dioses también se descomponen. ¡Dios ha muerto! ¡Dios permanece muerto! ¡Y nosotros le dimos muerte! ¿Cómo consolarnos nosotros, asesinos entre los asesinos? Lo más sagrado, lo más poderoso que había hasta ahora en el mundo ha teñido con su sangre nuestro cuchillo. ¿Quién borrará esa mancha de sangre? ¿Qué agua servirá para purificarnos? ¿Qué expiaciones, qué ceremonias sagradas tendremos que inventar? La magnitud de este acto ¿no es demasido grande para nosotros? ¿Tendremos que convertirnos en dioses o, al menos, que parecer dignos de los dioses? Jamás hubo acción más grandiosa, y los que nazcan después de nosotros pertenecerán, a causa de ella, a una historia más elevada que lo que fue nunca historia alguna".

Al llegar a este punto calló el loco y volvió a mirar a sus oyentes: también ellos callaron, mirándole con asombro. Luego tiró al suelo la linterna, de modo que se apag6 y se hizo pedazos.

"Vine demasiado pronto - dijo entonces-; mi tiempo no es aún llegado. Ese acontecimiento inmenso esı́a todavía en camino, viene andando; más aún no ha llegado a los oídos de los hombres. Han menester tiempo el relámpago y el trueno, la luz de los astros ha menester tiempo; lo han menester los actos, hasta después de realizados, para ser vistos y entendidos. Ese acto está 
todavía más lejos de los hombres que la estrella más lejana. ¡Y sin embargo ellos lo han ejecutado!".

Se añade que el loco penetró el mismo día en muchas iglesias y entonó su requiem aeternam Deo. Expulsado y preguntado por qué lo hacía, contestaba siempre lo mismo: " ¿De qué sirven estas iglesias, si no son los sepulcros y los monumentos de Dios?" (La gaya ciencia, n. 125.)

\section{Comentario}

Como apreciación personal, me parece que estamos ante un texto literariamente genial, que logra comunicar el vértigo que el romanticismo de Jean Paul quizás no conseguía transmitir. A pesar de eso, y aunque no soy ninguna autoridad en historia de la filosofía, tengo la convicción de que esta famosa página de Nietzsche está muy influida por el discurso de nuestro primer autor. Algunos puntos merecen destacarsc:

a) Un mar vacío (el mar del ser), un espacio sin horizonte, una tierra sin órbita ni norte en su movimiento, una carencia de puntos cardinales: ni atrás, ni delante, ni abajo ni arriba..., una nada infinta. Son todas ellas expresiones de la ausencia radical de sentido, y de un sentido experimentado como necesario.

b) Esta ausencia de sentido es obra nuestra: Nietzsche está hablando de un sentido que nosotros hemos tenido, que los cristianos han tenido. No de una noción "general" de Dios, sino del Dios "revelado". Está hablando de una fe perdida más que de un Dios nunca conocido (la biograffa de Nietzsche parece confirmar esta interpretación que, a su vez, ratifica lo dicho en nuestra Introducción). Ese Dios cristiano era "lo más sagrado y lo más poderoso", por eso su supresión es la acción "más grandiosa"; tanto que quizá sea "demasiado grande". Buena parte de la obra posicrior de Nietzsche es un azote a todos los que trivializan ese acto.

c) Conviene destacar también el carácter lúcido y profético de la visión de Nietzsche. El "loco" sabe que ha venido demasido pronto, pero sabe que lo que anuncia llegará: lee en su hora histórica, más que el "acta de defunción" de Dios, el germen fatal de esa muerte: como el que logra captar la luz de los astros cuando todavía se desplazan por el espacio cósmico, antes de que llegue hasta nosotros. En lodo esto, nuestro texto ha sido soprendentemente profético.

d) Ese asesinato no parece ser tanto (o sólo) obra de los ateos, sino obra de los creyentes. También Nietzsche se adelanta aquí al posterior reconocimiento dcl Vaticano II sobre la culpa que corresponde a las iglesias en esa muerte de Dios. Ellas, con su vivir para sf mismas y divinizar ese vivir para sí, se convirtieron en "tumbas de Dios". Ora pincelada cuyo vigor profético percibimos hoy mejor que en el XIX. 
e) Pero, a través de su deformación, las iglesias aún transmitran "algo" del Dios de Jesús, suficiente para comprender el vérligo que puede provocar su desaparición. Algo que el propio Nielzsche había barruntado y buscado loda su vida $^{6}$. Por eso no tolera que se banalice la muerte de Dios, como veremos que ocurre en sus sucesores. Y por eso se lanza a la búsqueda desesperada y heroica de una salida optimista: a una verdadera "creación desde la nada", tanto del sentido, como de los valores. Esa será la tarea del superhombre?, pero es una tarea absurda. La locura a la que va a parar Nietzsche es, en mi opinión, un homenaje a Dios infinitamente más digno de El que toda la frivolidad con que toman su Nombre muchos creyentes y no creyentes. Por algo se firmaba a veces: "el crucificado".

Y lo que Nietzsche expresó de manera poética, lo formula de manera menos pasional, más precisa filosoficamente, pero menos impactante existencialmente, el siguiente texto de J. P. Sartre.

\subsection{Texto}

El hombre es el ser que proyecta ser Dios... Ser hombre es tender a ser Dios... El hombre es fundamentalmente deseo de ser Dios... la realidad humana... pretende equipararse al Ens causa sui que la religión llama Dios. Asl la pasión del hombre es el reverso de la pasión de Cristo, porque el hombre se pierde en cuanto hombre para que nazca Dios. Pero la idea de Dios es contradicloria y nos perdemos inútilmente: el hombre es una pasión inútil. (J. P. Sartre, El ser y la nada (Buenos Aires 1966) 691 y 747.)

\section{Comentario}

La alusión a la pasión del hombre como pasión de Cristo evoca a aquel Nietzsche que se firmaba "el crucificado". También la concepción sartriana de la libertad humana como absoluta, como previa a toda esencia, parece muy cercana del proyecto nietzscheano de re-crear lodos los valores. Sin embargo, como la aventura de Nietzsche, tampoco tiene sentido. No queda pues más que accptar el sinsentido: el hombre es pasión inútil. Ahora lo sabe, y tendrá que saber convivir con lo que es.

De este modo, el texto de Sartre nos sirve de puente hacia el próximo capitulo. Porque el intento siguiente ya no será el de crear al superhombre, sino el de que el hombre no sea tanta pasión, para que no sea tan inútil: si Dios es contradictorio. y el superhombre una locura, sólo queda estar bien donde estamos. 


\section{E. Tierno Galván: ¡No hay para tanto! No hay "más allá" ni futuro, ni superhombre, pero hay un "acá".}

\section{Texto}

En la proposición "yo soy agnóslico" se descubre algo que impide lo otro [el anhelo de Dios], en cuanto la proposición equivale a esta otra: "yo vivo perfeclamente en la finitud y no necesito más"... El agnosticismo no es existencial, y este carácter de no ser atributo esencial de la existencia, le permite integrarse al agnóstico en la finitud con toda perfección... Ser agnostico es no echar de menos a Dios...

Cuando hablo de "finito" me refiero principalmente a la realidad material e inmaterial que constituye lo que existe, poniéndolo en contraposición a lo trascendente, para cualificar al agnóstico como el hombre que está perfectamente instalado en la finitud, en lo que llamamos materia y en lo que llamamos espíritu...

El ateo creció como contradicción lógica y vital del creyente, pero el agnóstico que ha superado la contradicción, ha tardado muchos siglos en aparecer y surge ahora como expresión del primado de la finitud y comienzo de la recuperación para la especie de lo que se ha quitado a la especie incluyendo la conciencia de la finitud en tanto que inefable... El género humano no puede aspirar a nada que esté fuera de sí mismo, ni que contradiga a su finitud. Donde el cristiano ha llegado y arraigado, la conciencia de la identificación con la finitud ha sido siempre imperfecta, aun cuando quienes defendlan, sabiéndolo o no, la necesidad de la conciencia de la identificación sin escapes ni resquicios, se creyeran al margen de los condicionamientos de la cultura cristiana. Un buen ejemplo sigue siendo el caso de Nietzsche pues, sin su fundamento cultural y creencial cristiano, sería inexplicable la exaltación del hombre a superhombre. Nietzsche "invirtio" el cristianismo de manera que, anclando su obra en la posición de donde partió, reaparece el modelo cristiano.

La insatisfacción del mundo nunca es insatisfacción que proceda del mundo en cuanto finitud, sino del mundo en cuanto resultado de la manipulación por parte de esa parte del mundo que llamamos hombre... [El agnóstico] tampoco es un optimista, es un hombre que está perfectamente instalado en la finitud. Estar perfectamente instalado en la finitud no significa "darse la buena vida". Los revolucionarios viven la satisfacción de la finitud quizá como sacrificio y esfuerzo... Ajustarse a la finitud... es fácil para el agnósti$\mathrm{co}$, puesto que lo finito es lo único que hay. Cualquier insatisfacción de lo finito en cuanto tal es enfermiza, pues en ella está implícita la pretensión de algo más bastante... cualquier idea respecto del humanismo que pretenda sacar al hombre de su seno propio, es decir, de la finilud, resulta de un modo 
u otro, contradictoria con lo que to humano es.

El agnóstico cree en la utopía del mundo. Conffa en que el conocimiento completo de lo línito lleve a una instalación del hombre en el mundo que coincida absolulamente con las exigencias de la especie. En este sentido la instalación perfecta en la finitud no implicaría asumir las contradicciones que hacen imperfecto lo finito ante el juicio de los hombres aquí y ahora, sino que el perfecto estar instalado coincidiría con la perfección objetiva de la finitud: es Jecir. se lograría la perfección de los hombres... No hay nada que más contradiga al hombre y a su finitud esencial que la sobrevida u otra vida. El agnóstico acepta el perecimiento, como acepta la vida y la lucha por la vida, es clecir. las condiciones de la finitud en la que hay que instalarse perfectamentc. (¿Qué es ser agnóstico?, Madrid 1975.)

\section{Comentario}

a) Tierno ha cambiado el significado de la palabra agnóslico: no es el que "no sabe". sino cl que no necesira saber.

No importa que luego afirme que el agnóstico no pregunta porque ya sabe que "lo finito es In único que hay" (lo que desde el punto de vista lógico-formal sería una "pctición de principio"). Lo importante es que la intensidad del drama niclzscheano ha acabado siendo insoportable (quizá contradictoria con las experiencias parciales de sentido que el hombre hace). Poi eso, en lugar de buscar una salida imposible en la superación del hombre, basta con aspirar a la "perfección de la finitud", dando por supuesto que las contradicciones de la finitud no son fordas atribuibles a ella, sino a su estado actual (al "aquí y ahora"). Tierno es, así, una nueva fase del proceso descrito, y confima que este proceso ha de entenderse no desde cualquier negación de Dios, sino desde la negación del Dios crisfiano: el proceso comenzó con el ateo como "contradicción lógica y vital del creyente", para concluir en el agnóstico (indiferente) como el que "pasa" no propiamente de Dios, sino de la pregunta y la inquietud que mueven al creyente.

b) Sorprende la insistencia con que el texto habla de una instalación perfecta en la linitud.

¿Es posible esa instalación perfecta? ¿O se trata de un esfuerzo ascético por negar como Buda el deseo (en este caso el deseo teologal), para ir a dar a una especic de "nirvana religioso"? La respuesta a esta cuestión dependerá mucho de to que se entienda por "Tinitud" $y$ de lo que se entienda por "deseo teologal". Tierno alimma creer en una utopia de la finitud, que no esıá claro si se alcánza sólo por el "conocimiento completo de lo finito" o por el sacrificio y esfuerzo revolucionario. ¿Aceptaría Tierno que el deseo teologal pueda fundar y alimenlar los mejorcs deseos (¡lambién quizá las mayores tentaciones!) del hombre? 
¿Podrá ocurrir entonces que (muerto el deseo teologal, y vistos los enormes precios y la inmensa graluidad que implica la utopía del mundo), el hombre decida que no tiene absolutamente ninguna razón para intentarla, porque ese intento le impediría la perfecta instalación en la finitud? Sartre también hubiera aceptado que "la insatisfacción de lo finito en cuanto (al es enfermiza", pero en cambio cree que esa enfermedad es la verdad más profunda del hombre. Tierno es aquí más heredero de Marx, porque cree decididamente en las posibilidades satisfactorias de una fínitud futura.

Por otro lado surge una pregunta contrapuesta: ¿y si fuese precisamente (no el deseo, pero sí) la confianza teologal lo que puede fundamentar esa instalación en la linitud? Los cristianos, a pesar de buscar el reino de Dios y su justicia, estaban obligados a decir "hágase la voluntad de Dios" con la misma paz con que Tierno parece aceptar que se cumpla "la voluntad de la finitud"...

c) Finalmente: estar perfectamente instalado en la finitud (incluso aun aceptando que no equivale a "darse la buena vida") cuesta mucho y hoy por hoy no es accesible a todos.

Tierno aclara, (y eso lo suscribiría en parte un cristiano) que ello no es debido a la finitud en cuanto tal, sino a "la manipulación por esa parte del mundo que llamamos hombre" (compárese con Rom 8, 20). Pero una vez producida esa manipulacion del mundo (cuya dificultad de arreglo suscita la sospecha razonable de que sea irreversible), ¿cabe todavfa esa instalación perfecta? ¿Puede llevarse a cabo sin renunciar a la solidaridad? Más aún: ¿pertenecen la solidaridad y el amor desprendido a esa instalación perfecta en la finitud? Tierno era radical en su deseo de no renunciar a ellos. ("Estar instalado en la finitud no significa darse la buena vida"). Pero cuando, luego de él, se equipara totalmente la ética al amor propio, ino se están poniendo los fundamentos para acabar con la solidaridad? Quiero aclarar que defiendo rabiosamente la dimensión ética del amor propio. Pero no que toda la ética se reduzca a él, ni aunque se pretenda que en ese amor propio están integrados los demás o que ese amor propio necesita ser "ilustrado". Pues tal integración de los otros en mí es, en realidad, escasológica. Aquí, en esta historia finita, sólo se da germinalmente, imperfectamente, y como llamada. Por eso, sólo en la escatología la ética será amor propio nada más. En esta historia, definir así la ética amenaza con degenerar (con el paso del tiempo, como ocurrí con el marxismo) en una universalización del propio yo, que ha sido la base élica de las derechas bien situadas pues sólo éstas pueden "integrar" a casi lodos los demás en su yo. Pero ¡de qué manera!...

d) De todos modos, el comentario al texto de Tiemo sólo cabe hacerlo en forma de preguntas, como he intentado hacer: pues a todas las objeciones que se le puedan poner, él podrá responder que provienen de una "enfermedad nietzschiana" ( 0 cristiana) aún no superada. $Y$ a todas las conclusiones negativas 
que se le puedan apuntar, responderá también esperando a ver si son validadas por la historia. El único punto ya establecido de su propuesta es la necesidad absoluta de "arreglar la finitud", en donde puede coincidir con esta otra formulación de un cristiano: sólo es posible seguir viviendo en este mundo tal como es, si se cree firmemente que no continuará siendo así, sino que llegará a ser como deber ser" (F. von Weizsäcker). Si ese "querer arreglarla" es compatible con la "perfecta instalación" en ella, es lo que permanece abierto por el momento. Pero hay que reconocer que, hoy por hoy, el horizonte que parece abrirse ante nosotros podría dar pie a un nuevo capítulo de esta historia, que cabria titular asi:

\section{De la "perfecta instalación" a la indiferencia}

Para este capítulo podemos echar mano de uno de los ideólogos de la postmodernidad, para quien cl narcisismo no parece tener un significado negativo, sino más bien positivo:

\subsection{Texto}

Todo él indiferencia, el desierto postmoderno está tan alejado del nihilismo universal "pasivo" y de su triste delectación en la inanidad universal, como del nihilismo "activo" y de su autodestrucción. Dios ha muerto, las grandes finalidades se apagan, pero a nadie le importa un bledo, ésta es la alegre novedad, ése es el límite del diagnóstico de Nietzsche respecto del oscurecimiento europeo. El vacío de sentido, el hundimiento de los ideales, no ha llevado, como cabía esperar, a más angustia, más absurdo, más pesimismo. Esa visión todavía religiosa y trágica se contradice con el aumento de la apatía de las masas, la cual no puede analizarse con categorlas de esplendor y decadencia, de afirmación y negación, de salud y enfermedad... "Es mejor cualquier sentido que ninguno" decía Nietzsche; hasta eso ya no es verdad hoy. La propia necesidad de sentido ha sido barrida y la existencia indiferente al sentido puede desplegarse sin patetismo ni abismo, sin aspiración a nuevas tablas de valores... Lejos de representar una profunda crisis del sistema... la deserción social no es más que su realización extrenza, su lógica fundamental, como si el capitalismo hubiera de hacer indiferentes a los hombres, como lo hizo con las cosas... Pensad lo que queráis de la tele, pero enchufadla... Surge una nueva indiferencia hacia el mundo a la que ya no acompaña siguiera el exlasis narcisista de la contemplación de uno mismo; hoy Narciso "se libera" envuelto en amplificadores, protegido por auriculares autosuficientes en su prótesis de sonidos graves. (G. Lipovetsky, La era del vacio (Barcelona 1986) 36, 38, 43, 44, 75. Las dos primeras frases en cursiva son del autor. La última y el texto en negrita mías.) 


\section{Comentario}

La buena noticia es ahora la indiferencia, el que ya no nos importa que Dios haya muerto, ni necesitamos aspirar a nuevos valores. El reverso de esa noticia podŕa ser que el afán de Tierno Galván por mejorar y transformar la finitud (aunque sea "con sacrificio y esfuerzo"), nos importa otro bledo. Desde Auschwitz o desde Bosnia quiza sigan surgiendo clamores estremecedores: sólo encontrarán nuestros oldos "protegidos por auriculares autosuficientes" o por conciertos de $24000 \mathrm{~W}$, "sin patetismo ni abismo". Por eso ha comentado alguien la curiosa evolución que sugieren los títulos de Lipovetsky: a "la era del vacio" le sigue cuatro años después "el imperio de lo efimero" y a éste "el crepúsculo del deber"'.

Para empalmar con ese último título, aunque desde otra 6ptica menos conformista, pueden servir estas líneas de Mario Benedetti, que aparecen en la prensa el mismo día en que concluyo este artículo.

\subsection{Texto}

Es cierto que el arrepentimiento se ha convertido en una industria lucrativa. Todos los dfas nos enteramos de que algún político, algún intelectual, algún politólogo, algún economista y sobre todo algún oportunista concurren al confesionario del Imperio, o a alguna de sus parroquias de moda, con toda su filatelia de pecados. En vez de elaborar el duelo de algún legítimo desencanto, reniegan allí de su pasado solidario, de su faena por causas justas, de su defensa de los derechos humanos, de su asco hacia la tortura. El mundo consumista los recibe con los brazos abiertos, y de paso les roba la billetera. No obstante, los privilegiados del canibalismo económico nunca los admitirán verdaderamente entre los suyos. Saben, como cualquier hijo de vecino, que en el mercado de la deslealtad el arrepentimiento no es la más fiable de las garantías. (El País, 25 de febrero 1994.)

Claro que Mario Benedetti es un escritor "tercermundista". En Europa ¡qué poquísimos suscribinian aún esas palabras!

\section{A modo de conclusión}

Lo que hemos intentado describir no son posiciones o decisiones éticas personales, sino la lógica inmanente a un proceso cultural. Desde mi óptica personal, que es una óptica cristiana, quisiera hacer ahora un par de reflexiones para terminar.

a) En mi opinión, el proceso descrito no es un proceso general de "increencia", sino que tiene que ver con el Dios cristiano. Es un proceso que comienza a incubarse en el def́smo, el cual afimnaba a Dios pero no podía creer 
en el amor y el interés solidario y débil de Dios por esta tierra: J. Messlier veía la superioridad del paganismo sobre el cristianismo en que los paganos sólo atribufan la divinidad a "grandes personajes de raras perfecciones", mientras que los cristianos la atribuyen a "un don-nadie..., insensato, fanático y malhechor". Y su admirador Voltaire no era de ningún modo ateo, pero no podía reconocer a Dios en un "conciudadano de ese pueblo odioso", que fue "colgado sin haber sido ungido" y que "se parecía a todos los desharrapados que gritan contra el gobierno y que acaban siendo jefes de partido o carne de patíbulo"'. Ahí está ya en germen el proceso que hemos descrito.

b) El proceso descrito quiź́ muestra bien hasta qué punto la fe es razonable ( ¿no racional!), pero también hasta qué punto es libre. Ambas cosas las ha enseñado siempre la teologla cristiana. Pero luego la praxis eclesiástica oficial ha procedido siempre como si la fe luese la única opción posible, de modo que el no creyente siempre cs mirado como ignorante (por no evangelizado), o perverso (porque no quiere creer), o enemigo. Este juicio es el que la Iglesia no puede emitir, porque sólo pertenece a Dios.

Más aún, mirándose en el espejo de Jesús, la Iglesia está llamada a sospechar que Dios habrá acogido a un Nietzsche (a pesar de su orgullo loco) mucho más Tavorablemente que a tantos fariseos que se amparan en El para blanquear su propia mezquindad, sin darse cuenta de que, al apelar ellos a Dios, incurten en la vicja condena de Isaías y de Pablo: "por vuestra culpa es blasfemado el nombre de Dios entre las gentes" (Rom 2, 24). La increencia efectivamente quita poder social a la Iglesia. Pero si la Iglesia quiere anunciar al Dios de Jesús (y no a sí misma), deberá aceptar ese supuesto despojo, como el padre de la parábola entregó a su hijo la herencia que le correspondía, sin privarle de ella "por su bien". Evangelización no es "reconquista", sino testimonio razonado de una esperanza vivida.

c) Un elemento fundamental de la esperanza cristiana es que, como fe, integra a todos los demás: es una esperanza "católica". Dios sigue actuando en la historia, incluso cuando los hombres crucifican a su Hijo, a través de esa fuerza discrela e imperceptible para nosotros, que llamamos Espínitu Santo, y que da fuerza al Hijo para entregarse (Heb 9, 14). Creer en el Dios de Jesús equivale a no molestarse por las negaciones o los ataques de otros, sino más bien por la falta de amor y solidaridad entre los hombres y hacia los más oprimidos, sabiendo que la realidad de Dios los abraza a todos, y que todos se integran en su economla cristológica: porque la realidad de Dios entraña absolutamente un significado transformador y no queda negada ( $\mathrm{ni}$ aunque se haga eso verbalmente), cuando se acepta ese significado: "todo el que ama ha nacido de Dios y ha conocido a Dios"lo.

Por eso ocurre que la palabra Dios es la más falsificable del lenguaje, y que la palabra ateo puede ser "veri-ficada" (reconvertida en verdad) por una vida solidaria. Todo esto pertenece a la fe en el Dios cristiano; y por eso el creyente

Digitalizado por Biblioteca "P. Florentino Idoate, S.J."

Universidad Centroamericana José Simeón Cañas 
no necesita "defender" a Dios ni "atacar" a Sus enemigos, sino sólo "estar dispuesto a dar razón de su esperanza, pero con mansedumbre y respeto" (IPe 3. 15.16). Esperanza y razón que se desvanecen cuando el cristiano hace "cruzadas" contra los no creyentes o contra los que le atacan". El cristiano detre preocuparse más de transparentar a Dios, que de defenderlo.

d) Hoy es frecuente escuchar que "todas las religiones son intolerantes". Sin querer escurrir ningún bulto, quiź valga la pena recordar que, hace una generación, lo que constantemente ofamos decir era que "todas las religiones son crimplices". No sé si ese cambio de acusaciones visibiliza algo de la evolución sugerida en este artículo. Pero probablemente las religiones -en sí mismas- no son intolerantes ni cómplices. Somos los hombres (religiosos o no) los que nos debatimos siempre entre ambos polos, sin conseguir encontrar una salida glohal y auténlica hacia una tolerancia que no sea complicidad, y una radicalidad que no sea intolerancia. No sé si esta síntesis ética imposible podría ser asimilada a la otra imposible síntesis ontológica cntre el "en-sî" y el "para-sî" que, scgún Sartrc. conslituye al hombre y le convierte en pasión inútil. No lo sé. Sólo me atrevería a sugerir que, si alguna salida hay hacia esa síntesis, no cabe buscarla en religión o irreligión, sino sólo por donde señalan estas palabras de un cristiano de los más hondamente creyentes, y de aquellos a quienes más difícil resulto la fe: "Hermanos, no lemáis los crimenes del hombre. Amadle a pesar de sus pecados, porque os acercáis al amor divino que es el supremo anor de la ticrra" (Dostoyevski).

e) Por último: si son válidas la evolución sugerida y las consecuencias apuntadas en este escrito, penmítaseme concluir con una sospecha dolorida: la de que la actual cruzada contra la increencia impostada por muchos cclesiásticos esté radicalmente falseada $Y$ que, de ser así, sólo contribuya a aumentar la increencia o, en lodo caso, a de Jormar la creencia cristiana.

\section{Notas:}

1. Y es importante notar que ambas tradiciones provienen del cristianismo: el autoritarismo de las iglesias se ha apoyado muchas veces en una inlagen del "Dios opresor" (coritra el que reacciona el texto 2.1.). A pesar de eso. y a traves de eso. lat vida cristiana había conservado suficientemente la confianza en un Dios salvador" (negado por el texio 1).

2. Cfr. MEW III. 142-143, y nótese ei cambio arbitrario de planteamientos: Stimer hablaba del Ser Supremo como fundamento ontológico del respelo al hoinbre. Marx le responde hablando sólo de la fintión social que la ideu Jel Ser Supremo ha jugado muchas veces.

3. MEW. III, 220. Marx no dice nada sobre qué es lo que obliga a huchar por e'se cambio de las circunstancias nateriales, que se revela tan enormenente dificil y sacrificado.

4. Una prueba de hasta qué punto Marx sigue prisionero de la misma milotogía pscudoprogresista del capitalismo, la tenemos en este texto que silaba hate pocit Reyes Mate. y en el que justifica la conqu:sta de medio iMéxico por Estiados Ĺnidos. 
aduciendo razones de progreso: "Bakunin reprochará a los americanos una guerra de conquista que, desde luego, asesta un rudo golpe a su teoría fundada en "la justicia y la humanidad", pero que fue llevada pura y sencillamente en interés de la civilización. ¿O es una desgracia que la espléndida California le fuera arrancada a los perezosos mexicanos que no sabían que hacer con ella?". (En AA. VV. Lo santo y lo sagrado, Madrid 1993, p. 192, subrayado mlo). Sin saberlo, ¡Marx habla aquí exactamente igual que Ginés de Sepúlveda cuando justifica la conquista de América por los españoles!

5. "La lglesia es exactamente aquello contra lo que predicó Jesús y contra lo que enseñó a luchar a sus discípulos". Otra frase de Nietzsche en sus escritos póstumos, que las iglesias deberfan meditar profundamente.

6. Valgan como ejemplo tres testimonios conocidos: una poesía juvenil, una frase del Zaratrusta, y una confesión a Ida, la mujer de su gran amigo F. Overbeck:

(a) "Te quiero conocer, Desconocido. Tú que me agarras en lo profundo del alma. Que surcas mi vida como una tormenta. Tú, Inaprensible, mi Semejante. Te quiero conocer, servirte quiero (Werke, ed. de A. Baumler, V, 457).

(b) "Vuelve atrás, con todos Tus suplicios. Vuelve al último de todos los solitarios. Todos los arroyos de mis lágrimas corren hacia Ti. Y la última llama de mi corazón arde hacia Ti. Vuelve mi Dios desconocido, mi dolor. mi úllima dicha" (parte III: "El encantador", ibid. IV. 2381. Este texto, con su mezcla de dolor y dicha, debió ser significativo para Nietzsche puesto que, con alguna supresión, se le encuentra también en el lamento de Ariadna de los Ditirambos dionisíacos).

(c) "No abandone usted jamás la idea de Dios. Seguramente usted la tiene sin darse cuenta. Yo la he abandonado; quiero crear algo nuevo, y no puedo ni quiero volverme atrás. Acabaré por sucumbir a esta pasión que me zarandea constantemente. Voy desmoronándome, pero esto nada me importa" (citado por E. Colomer, "Nietzsche y la muerte de Dios", en Orbis Catholicus, marzo 1963, p. 22. También parcialmente en H. Küng, ¿Existe Dios? (Madrid 1979) 539-540).

7. "El hombre es algo que debe ser superado. ¿Qué habéis hecho vosotros para superarlo?", dirá el tercer prefacio del Zaratusira.

8. Esta evolución se comprenderá mejor si tenemos en cuenta que el primer título no alude primariamente al vacío "de sentido", sino a lo que el autor denomina "vaclo emocional", a la "indiferencia pura" (ver cap. 2 de este primer libro).

9. Textos en B. Cottret, Le Christ des Lumières (1660-1760), París 1990, 157 y 164.

10. 1 Juan 4, 7. La manera como formulo en el texto alude a la frase otras veces comentada de K. Barth: "en lo grande y en lo pequeño, en lo universal y en lo particular, en la totalidad de su existencia como hombres, todos deben vivir con el hecho no sólo iluminador, sino real y absolutamente transformador, de que Dios existe" (Kirchliche Dogmatik II, 1, 289). La ultimidad de la fe no estará pues en lo que se afirme con las palabras, sino en cómo se vive con ese hecho.

11. Por eso, la exhortación de la primera carta de Pedro que acabo de citar se enmarca en consejos como éstos: "sed amantes de vuestros hermanos, de blandas entrañas..., no devolviendo mal por mal ni afrenta por afrenta, antes al contrario bendiciendo, ya que para esto fuisteis llamados, para heredar una bendición... (pues) iquién será el que os dañe si fuisteis militantes de la bondad?" (vv. 8.9.13). Quisiera llamar la atención sobre esta úllima y sobrecogedora formulación. 